\title{
Enhanced production of thermostable laccases from a native strain of Pycnoporus sanguineus using central composite design"
}

\author{
Leticia I. RAMÍREZ-CAVAZOS ${ }^{1}$, Charles JUNGHANNS² ${ }^{2}$ Rakesh NAIR ${ }^{3}$, Diana L. CÁRDENAS-CHÁVEZ ${ }^{1}$, \\ Carlos HERNÁNDEZ-LUNA ${ }^{4}$, Spiros N. AGATHOS ${ }^{3}$, Roberto PARRA ${ }^{\dagger 1}$ \\ $\left({ }^{1}\right.$ Centro del Agua para América Latina y el Caribe, Tecnológico de Monterrey, Campus Monterrey, NL 64849, Mexico) \\ $\left({ }^{2}\right.$ Helmholtz Centre for Environmental Research-UFZ, Permoserstraße 15, 04318 Leipzig, Germany) \\ ( ${ }^{3}$ Bioengineering Group, Earth and Life Institute, Université Catholique de Louvain, \\ Place Croix du Sud, 2, Box L7.05.19, 1348 Louvain-la-Neuve, Belgium) \\ ( ${ }^{4}$ Laboratorio de Enzimología, Facultad de Ciencias Biológicas, Universidad Autónoma de Nuevo León, \\ Av. Universidad s/n, Ciudad Universitaria, San Nicolás de los Garza, NL 64450, Mexico) \\ †E-mail: r.parra@itesm.mx
}

Received Sept. 12, 2013; Revision accepted Feb. 19, 2014; Crosschecked Mar. 10, 2014

\begin{abstract}
The production of thermostable laccases from a native strain of the white-rot fungus Pycnoporus sanguineus isolated in Mexico was enhanced by testing different media and a combination of inducers including copper sulfate $\left(\mathrm{CuSO}_{4}\right)$. The best conditions obtained from screening experiments in shaken flasks using tomato juice, $\mathrm{CuSO}_{4}$, and soybean oil were integrated in an experimental design. Enhanced levels of tomato juice as the medium, $\mathrm{CuSO}_{4}$ and soybean oil as inducers $(36.8 \%(\mathrm{v} / \mathrm{v}), 3 \mathrm{mmol} / \mathrm{L}$, and $1 \%(\mathrm{v} / \mathrm{v})$, respectively) were determined for $10 \mathrm{~L}$ stirred tank bioreactor runs. This combination resulted in laccase titer of $143000 \mathrm{IU} / \mathrm{L}$ (2,2'-azino-bis(3-ethylbenzthiazoline-6sulfonic acid), $\mathrm{pH} 3.0$ ), which represents the highest activity so far reported for $P$. sanguineus in a 10-L fermentor. Other interesting media resulting from the screening included glucose-bactopeptone which increased laccase activity up to $20000 \mathrm{IU} / \mathrm{L}$, whereas the inducers Acid Blue 62 and Reactive Blue 19 enhanced enzyme production in this medium 10 times. Based on a partial characterization, the laccases of this strain are especially promising in terms of thermostability (half-life of $6.1 \mathrm{~h}$ at $60^{\circ} \mathrm{C}$ ) and activity titers.
\end{abstract}

Key words: Enhanced laccase production, Central composite design, Screening media, Inducers, Tomato juice medium, Soybean oil, Copper sulfate doi: $10.1631 /$ jzus.B1300246

Document code: A

CLC number: Q936

\section{Introduction}

There is a growing interest in the development of eco-friendly processes to reduce the environmental impact of today's industries. Therefore, the search for enzymes capable of substituting conventional chemical methods in the synthesis of commercial products and the transformation of highly toxic compounds

\footnotetext{
${ }^{\ddagger}$ Corresponding author

* Project supported by the National Science and Technology Council of Mexico (CONACYT) (No. 192118)

(C) Zhejiang University and Springer-Verlag Berlin Heidelberg 2014
}

into non-toxic species has received considerable attention (Rodríguez-Couto et al., 2009; Kudanga et al., 2011). Laccases (EC 1.10.3.2) are an example of enzymes which catalyze the oxidation of a wide range of arylamines or phenols (Gochev and Krastanov, 2007). These multi-copper oxidases combine the four-electron reduction of dioxygen to water with the one-electron oxidation of four substrate molecules. They have low substrate specificity and thus oxidize a variety of substrates, either natural or xenobiotic (Bertrand et al., 2002). Laccases are naturally produced by fungi, plants, and certain bacteria or insects (Bertrand et al., 2002). Previous studies have reported 
laccase production at laboratory scale using wild-type strains of white-rot fungi or basidiomycetes (e.g., Pycnoporus strains), but the low level of production by non-genetically modified organisms (non-GMOs) and the costs of producing bulk amounts have hampered industrial applications.

There are multiple factors influencing laccase production. Laccase synthesis has been found to be highly dependent on cultivation conditions and growth medium composition. For the medium, the most influential parameters are carbon availability, micro-elements, the nitrogen source, and its concentration (Gochev and Krastanov, 2007). Many reports have focused on media, inducers, and operational conditions to maximize fungal laccase production (Galhaup and Haltrich, 2001; Vanhulle et al., 2007a; Junghanns et al., 2008). Some of them took costs and scalability into consideration (Osma et al., 2011). Reducing costs of laccase production by optimizing the fermentation medium and conditions remains one of the basic research objectives at the industrial level (Rodríguez-Couto and Toca-Herrera, 2007). As the carbon sources present in the medium play an important role in ligninolytic enzyme production (Eggert et al., 1996), different commercial products have been tested. Tomato-juice-based media were appropriate for cultivation of different fungal species under laboratory conditions and sufficient for laccase production (Ullrich et al., 2005; Michniewicz et al., 2006; Liers et al., 2007; Junghanns et al., 2008; Mueangtoom et al., 2010). Malt-extract and bran-flake media have been used to produce laccase specifically from $P y c$ noporus sanguineus (Trovaslet et al., 2007; DantánGonzález et al., 2008). The addition of various supplements to the medium, for example low concentrations of copper, also stimulated laccase expression (Lee et al., 1999; Palmieri et al., 2000). Other inducers with structural similarities to lignin such as xylidine, ferulic acid, and gallic acid are often applied as they usually increase laccase activity (Bollag and Leonowicz, 1984; Pointing et al., 2000; Galhaup et al., 2002; Kunamneni et al., 2007). Because of their similarities to certain lignin structures, anthraquinone dyes such as Reactive Blue 19 and Acid Blue 62 have been tested to enhance laccase production (Junghanns et al., 2008). Soybean oil was further reported to greatly increase laccase activities in cultures of Trametes pubescens and Botryosphaeria rhodina
(Dekker et al., 2007; Osma et al., 2007).

In the present work, different media, novel inducers, and critical parameters (temperature, $\mathrm{pH}$, and time of harvesting) were investigated in order to enhance the production of thermostable laccases from a native strain of $P$. sanguineus, CS43. CS43 laccases exhibited interesting catalytic properties and higher thermostability at 50 and $60^{\circ} \mathrm{C}$. A design of experiment (DOE) was performed to evaluate the feasibility of scale-up using a relatively economic culture medium, making possible its future industrial applications.

\section{Materials and methods}

\subsection{Chemicals}

Malt extract was obtained from Difco (BD Diagnostics, Sparks, USA). Distilled water was used for dilution and preparation of solutions. The dyes Acid Blue 62 and Reactive Blue 19 were obtained from Acros Organics (Geel, Belgium). Tomato juice (Delhaize Group, Belgium) was used as a commercially available item. All other chemicals were of analytical grade and were purchased from SigmaAldrich (St. Louis, USA).

\subsection{Microorganism}

The white-rot fungus $P$. sanguineus (CS43) was obtained from a culture collection of the Universidad Autónoma de Nuevo Leon, Mexico. It was maintained at $4{ }^{\circ} \mathrm{C}$ and sub-cultured weekly on $2 \%(\mathrm{w} / \mathrm{v})$ malt extract agar plates at $30{ }^{\circ} \mathrm{C}$ prior to production experiments.

\subsection{Screening culture conditions}

Three, nine, and fifteen plugs of $5 \mathrm{~mm}$ diameter were taken from the active borders of malt extract agar cultures and transferred to Erlenmeyer flasks $(100,250$, and $500 \mathrm{ml})$ for pre-cultures containing 37 , 100 , and $200 \mathrm{ml}$, respectively, of control medium: glucose $(40 \mathrm{~g} / \mathrm{L})$, meat peptone $(15 \mathrm{~g} / \mathrm{L})$, yeast extract $(5 \mathrm{~g} / \mathrm{L})$, and magnesium sulfate $(0.5 \mathrm{~g} / \mathrm{L})$. For stirred tank bioreactor precultures (in $500 \mathrm{ml}$ flasks), the same control medium was employed but glucose and meat peptone concentrations were 36 and $10 \mathrm{~g} / \mathrm{L}$, respectively, as described for optimized media. After $7 \mathrm{~d}$ of incubation $\left(30{ }^{\circ} \mathrm{C}, 150 \mathrm{r} / \mathrm{min}\right)$, pre-cultures were used to inoculate all experimental cultures. The 
following media were tested: control medium, bran flakes 3\% (w/v) (Dantán-González et al., 2008), malt extract $2 \%(\mathrm{v} / \mathrm{v})$ (Trovaslet et al., 2007), tomato juice $13 \%$ (v/v) (Michniewicz et al., 2006; Junghanns et al., 2008), and glucose-bactopeptone (Nair et al., 2013). Flasks were incubated in a shaker at $30{ }^{\circ} \mathrm{C}$ with continuous agitation $(150 \mathrm{r} / \mathrm{min})$. After $2 \mathrm{~d}$ of inoculation, laccase production was induced by $3 \mathrm{mmol} / \mathrm{L}$ copper sulfate $\left(\mathrm{CuSO}_{4}\right)$ (Galhaup et al., 2002). For the screening of additional inducers in control medium, the following compounds were added together with $\mathrm{CuSO}_{4}$ : soybean oil 1\% (Osma et al., 2007), ferulic acid $0.5 \mathrm{mmol} / \mathrm{L}$ (Vanhulle et al., 2007a) and gallic acid $1 \mathrm{mmol} / \mathrm{L}$ (Galhaup et al., 2002) dissolved in $50 \%$ ethanol, xylidine $20 \mu \mathrm{mol} / \mathrm{L}$ (Pointing et al., 2000), Acid Blue $620.48 \mathrm{mmol} / \mathrm{L}$ or Reactive Blue 19 $0.71 \mathrm{mmol} / \mathrm{L}$ (Vanhulle et al., 2007b). Three levels of $\mathrm{CuSO}_{4}(1,3$, and $5 \mathrm{mmol} / \mathrm{L})$ were independently tested using the control medium. Samples from triplicate flasks or stirred tank bioreactor were taken periodically and centrifuged (13000 r/min for $15 \mathrm{~min}$ ), and the clear supernatant was assayed for enzyme activity (see Section 2.5).

\subsection{Bioreactor cultivation}

Each culture was carried out in a 10-L stirred tank bioreactor (BioStat Bplus, Sartorius Stedim, Germany) with a working volume of $8 \mathrm{~L}$. It was equipped with $\mathrm{pH}$ and dissolved oxygen concentration $\left(\mathrm{pO}_{2}\right)$ sensors and an agitator with three standard pitch blade turbine impellers, each one with three cross blades. Temperature $\left(30{ }^{\circ} \mathrm{C}\right)$, agitation $(150 \mathrm{r} / \mathrm{min})$, and aeration with compressed air (0.3 air volume flow per volume of medium per minute (vvm)) were kept constant throughout the cultivation. Bioreactor and culture medium were sterilized at $121^{\circ} \mathrm{C}$ for $40 \mathrm{~min}$. The culture medium based on commercial tomato juice $36.8 \%$ was inoculated with $800 \mathrm{ml}$ of the homogenized 7 d pre-culture. Sterile antifoam 204 ( $121{ }^{\circ} \mathrm{C}$ for $21 \mathrm{~min}$ ) was added during the first hours of cultivation (Rogalski et al., 2011). Laccase induction was carried out at the second day by adding $3 \mathrm{mmol} / \mathrm{L} \mathrm{CuSO}_{4}$ and $1 \%$ sterile soybean oil $\left(121{ }^{\circ} \mathrm{C}\right.$ for $21 \mathrm{~min}$ ). Parallel to the bioreactor runs, $250 \mathrm{ml}$ flasks were prepared with the same medium concentrations as the reactor with or without induction after $48 \mathrm{~h}$. Both conditions were investigated in triplicate.

\subsection{Laccase activity assay}

Laccase activity was determined with 2,2'-azinobis(3-ethylbenzthiazoline-6-sulfonic acid) (ABTS) as substrate. The assay mixture containing $0.5 \mathrm{mmol} / \mathrm{L}$ ABTS $(20 \mu \mathrm{l}), 0.1 \mathrm{~mol} / \mathrm{L}$ citrate $/ 0.2 \mathrm{~mol} / \mathrm{L}$ phosphate buffer $(160 \mu \mathrm{l})$ at $\mathrm{pH} 3$ and diluted supernatant $(20 \mu \mathrm{l})$ was incubated at $25{ }^{\circ} \mathrm{C}$. Oxidation of ABTS was monitored by the increase in the absorbance at $420 \mathrm{~nm}$ $\left(A_{420}, \varepsilon=3.6 \times 10^{4} \mathrm{~L} /(\mathrm{mol} \cdot \mathrm{cm})\right)$ using a microplate reader (Powerwave XS2, Bio-Tek, Bad Friedrichshall, Germany) (Eggert et al., 1996; Nair et al., 2013). Enzyme activities were expressed as international units (IU); under the conditions of the experiment, one IU corresponds to $1 \mu \mathrm{mol}$ of product formed per minute.

\subsection{Experimental design and data treatment}

The DOE approach was performed using a central composite design (CCD) with tomato juice medium, $\mathrm{CuSO}_{4}$ and soybean oil concentrations as factors since they showed the best screening results. A complete two-level factorial design with one central and six axial points with three replicates each for a total of 45 flasks was performed. Levels used for each factor are given in Table 1. The analysis was performed with the experimental design module of Statistica 10 (SoftStat Inc., 1984-2011, USA).

Table 1 Tested levels of tomato juice medium, $\mathrm{CuSO}_{4}$ and soybean oil in the CCD experiment

\begin{tabular}{cccc}
\hline Level & $\begin{array}{c}\text { Tomato juice } \\
(\%, \mathrm{v} / \mathrm{v})\end{array}$ & $\begin{array}{c}\mathrm{CuSO}_{4} \\
(\mathrm{mmol} / \mathrm{L})\end{array}$ & $\begin{array}{c}\text { Soybean oil } \\
(\%, \mathrm{v} / \mathrm{v})\end{array}$ \\
\hline $\mathrm{a}$ & 3.18 & 1.32 & 0.16 \\
-1 & 10.00 & 2.00 & 0.50 \\
0 & 20.00 & 3.00 & 1.00 \\
1 & 30.00 & 4.00 & 1.50 \\
$\mathrm{~A}$ & 36.82 & 4.68 & 1.84 \\
\hline
\end{tabular}

\section{Results}

\subsection{Screening of media and inducers}

Hernández-Luna et al. (2008) isolated 15 basidiomycete strains with extensive dye decolorization capacity from a total of 92 isolates from Northeast Mexico. Two of these strains, $P$. sanguineus CS2 and CS43, were selected for the present study. Table 2 indicates that CS2 and CS43 strains had similar titers 
of laccase employing glucose-meat peptone medium previously optimized for each strain (data not shown). Under these conditions, the half-life of CS43 laccases present in the culture supernatant was $22 \%$ and $5 \%$ higher than that of CS2 at 50 and $60{ }^{\circ} \mathrm{C}$, respectively. Therefore, strain CS43 was selected for subsequent experiments. The first one was carried out in flasks of $100 \mathrm{ml}$ and consisted of a screening of media, combinations of inducers and three concentration levels of $\mathrm{CuSO}_{4}$ as described in Section 2. The culture media which gave the highest laccase activities were tomato juice medium and glucose-bactopeptone medium, averaging approximately $20000 \mathrm{IU} / \mathrm{L}$ of laccase activity on Day 22, corresponding to a 42 -fold increase in activity compared with the control (Fig. 1a). Bran flake medium and malt extract medium gave 28 times higher laccase activities than the control (Fig. 1a). Tomato juice medium was chosen for further investigation because it is less expensive than the mixture of components required for glucose-bactopeptone medium.

Table 2 Laccase activities and half-lives in cultures of CS2 and CS43 using an optimized medium

\begin{tabular}{ccccccc}
\hline \multirow{2}{*}{$\begin{array}{c}P . \\
\text { sanguineus } \\
\text { strain }\end{array}$} & \multicolumn{2}{c}{ Optimal production } & & \multicolumn{3}{c}{ Half-life (h) } \\
\cline { 2 - 3 } \cline { 6 - 7 } & $\begin{array}{c}\text { Laccase } \\
\text { activity } \\
\text { (IU/L) }\end{array}$ & $\begin{array}{c}\text { Culture } \\
\text { period } \\
(\mathrm{d})\end{array}$ & & $50^{\circ} \mathrm{C}$ & $60{ }^{\circ} \mathrm{C}$ & $70^{\circ} \mathrm{C}$ \\
\hline $\mathrm{CS} 43$ & 5806 & 28 & & 27.7 & 6.1 & 1.2 \\
$\mathrm{CS} 2$ & 4840 & 23 & & 22.8 & 5.7 & 1.6 \\
\hline
\end{tabular}

* Optimized medium contains glucose $40 \mathrm{~g} / \mathrm{L}$ and meat peptone $15 \mathrm{~g} / \mathrm{L}$ for CS43 or $36 \mathrm{~g} / \mathrm{L}$ and $10 \mathrm{~g} / \mathrm{L}$, respectively, for CS2

The influence of different inducers on the laccase activity is shown in Fig. 1b. All the tested inducers had a significant effect on laccase production on culture Day 18 with the exception of gallic acid. The best result for laccase induction was obtained with soybean oil, resulting in a 45 -fold increase (45000 IU/L) in enzyme activity compared to the control. The two dyes tested, Acid Blue 62 and Reactive Blue 19, resulted in similar laccase activities, about 10 times higher than that of the control. Ferulic acid and xylidine induced cultures only produced 5.0 and 2.5 times more laccase activity than the control, respectively.

The maximum activity obtained in the testing of different $\mathrm{CuSO}_{4}$ levels was achieved on Day 36
$(17700 \mathrm{IU} / \mathrm{L}$ at $5 \mathrm{mmol} / \mathrm{L})$. However, to ensure comparability with the other experiments, the results were analyzed on Day 18 (Fig. 1c). The two highest activities were produced by $\mathrm{CuSO}_{4} 5$ and $3 \mathrm{mmol} / \mathrm{L}$ with no significant difference in their averages, around $1150 \mathrm{IU} / \mathrm{L}$.
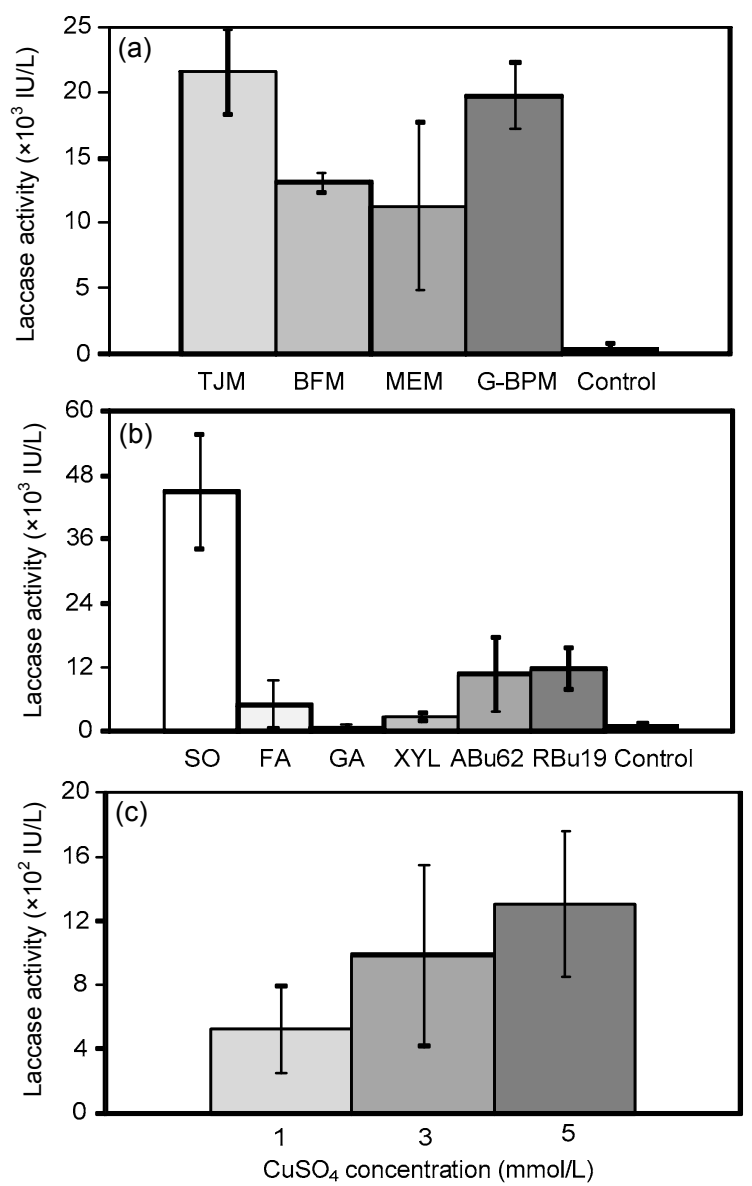

Fig. 1 Independent screening results for laccase activity (a) Laccase activities on culture Day 22 using different media: tomato juice medium (TJM), bran flake medium (BFM), malt extract medium (MEM), glucose-bactopeptone medium (G-BPM), and control (glucose-meat peptone medium). All flasks were induced with $\mathrm{CuSO}_{4}(3 \mathrm{mmol} / \mathrm{L}) 24 \mathrm{~h}$ after inoculation. (b) Laccase activities using different inducer-combinations after $18 \mathrm{~d}$ : soybean oil (SO), ferulic acid (FA), gallic acid (GA), xylidine (XYL), Acid Blue 62 (ABu62), Reactive Blue 19 (RBu19), and control (induced with $\mathrm{CuSO}_{4}$ ). (c) Laccase activities on culture Day 18 observed in cultures with different $\mathrm{CuSO}_{4}$ levels: 1,3 , and $5 \mathrm{mmol} / \mathrm{L}$ ( $3 \mathrm{mmol} / \mathrm{L}$ was used as control). Data are expressed as mean \pm standard deviation of triplicate experiments

\subsection{Enhancement of CS43 laccase production}

The next step to enhance the production of thermostable laccases by CS43 strain was to integrate 
the best screening results into a statistical DOE. Table 3 summarizes the mean of laccase activity obtained from the CCD experiment in relation to different conditions on culture Day 14 when the higher enzymatic activity was reached. The best condition achieved $52538 \mathrm{IU} / \mathrm{L}$ of laccase activity (treatment No. 15) when tomato juice medium was at the highest level whereas $\mathrm{CuSO}_{4}$ and soybean oil were in the central level.

An analysis of variance (ANOVA) was subsequently performed to validate the results observed in the CCD (Table 4). Although the interaction of $\mathrm{CuSO}_{4}$ with soybean oil $(P<0.05)$ is important, the tomato juice medium and $\mathrm{CuSO}_{4}$ concentrations and the interaction of both concentrations were the most

Table 3 Treatments used for the CCD and laccase activities obtained at culture

\begin{tabular}{|c|c|c|c|c|c|}
\hline \multirow[t]{2}{*}{ No. } & \multicolumn{3}{|c|}{ Level } & \multicolumn{2}{|c|}{$\begin{array}{c}\text { Laccase activity } \\
\text { (IU/L) }\end{array}$} \\
\hline & TJM & $\mathrm{CuSO}_{4}$ & SO & Exp. mean & $\mathrm{SE}$ \\
\hline 1 & -1.682 & 0 & 0 & 2.7 & 37.8 \\
\hline 2 & -1 & -1 & -1 & 4511.5 & 17.8 \\
\hline 3 & -1 & 1 & -1 & 4.7 & 9.9 \\
\hline 4 & -1 & -1 & 1 & 2775.1 & 5.6 \\
\hline 5 & -1 & 1 & 1 & 4.6 & 21.9 \\
\hline 6 & 0 & 0 & -1.682 & 8711.5 & 2.9 \\
\hline 7 & 0 & -1.682 & 0 & 37099.9 & 10.8 \\
\hline 8 & 0 & 0 & 0 & 7913.1 & 42.3 \\
\hline 9 & 0 & 1.682 & 0 & 7452.6 & 26.6 \\
\hline 10 & 0 & 0 & 1.682 & 9471.8 & 37.9 \\
\hline 11 & 1 & -1 & -1 & 44203.0 & 9.8 \\
\hline 12 & 1 & 1 & -1 & 19232.6 & 13.6 \\
\hline 13 & 1 & -1 & 1 & 36728.8 & 11.5 \\
\hline 14 & 1 & 1 & 1 & 26663.5 & 17.9 \\
\hline 15 & 1.682 & 0 & 0 & 52538.2 & 22.7 \\
\hline
\end{tabular}

TJM: tomato juice medium; SO: soybean oil; Exp.: experimental; SE: standard error significant factors in laccase production $(P \leq 0.001)$. Using a regression over the response surface, a prediction equation was generated (Eq. (1)). Fig. 2 shows the model fit for the observed vs. predicted effects on laccase activity, and a good correlation with the experimental data was obtained $\left(r^{2}=0.94, P<0.001\right)$. The graph indicated that no significant violations of the model were found in the analysis. The best resultbased model was obtained at high tomato juice medium concentration and lower levels of $\mathrm{CuSO}_{4}$ and soybean oil. As the $\mathrm{CuSO}_{4}$ level increased, the soybean oil level should be increased for better results.

$$
\begin{aligned}
Y= & 8514.1+15222.1 c_{\mathrm{TJM}}-6749.3 c_{\mathrm{CuSO}_{4}}+ \\
& 5658.6 c_{\mathrm{TJM}}^{2}+4246.4 c_{\mathrm{CuSO}_{4}}^{2}- \\
& 3469.8 c_{\mathrm{TJM}} c_{\mathrm{CuSO}_{4}}+2080.2 c_{\mathrm{SO}} c_{\mathrm{CuSO}_{4}},
\end{aligned}
$$

where $Y$ is the laccase activity predicted, $c_{\mathrm{TJM}}, c_{\mathrm{CuSO} 4}$, and $c_{\mathrm{SO}}$ are the concentrations of tomato juice medium, $\mathrm{CuSO}_{4}$, and soybean oil, respectively.

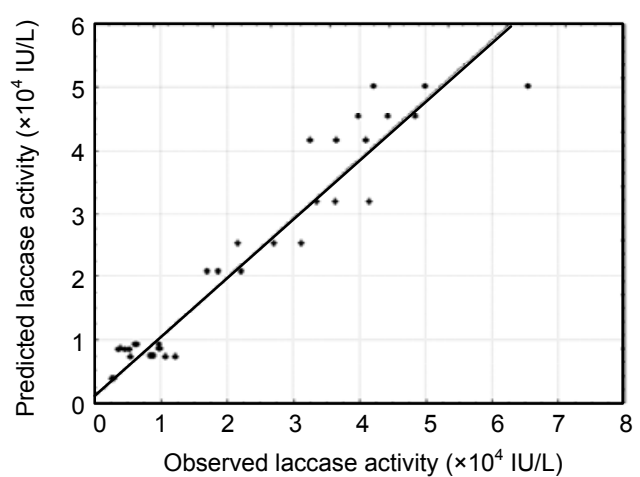

Fig. 2 Plot of observed vs. predicted values of laccase activity on culture Day 14 from the DOE experimental

\begin{tabular}{|c|c|c|c|c|c|}
\hline Variable & Sum of squares & $d f$ & Mean squares & $F$-value & $P$-value \\
\hline TJM (L) & $9.4933 \times 10^{9}$ & 1 & $9.4933 \times 10^{9}$ & 418.7828 & 0.000000 \\
\hline TJM (Q) & $5.8142 \times 10^{8}$ & 1 & $5.8142 \times 10^{8}$ & 25.6484 & 0.000013 \\
\hline SO (L) & $5.5139 \times 10^{4}$ & 1 & $5.5139 \times 10^{4}$ & 0.0024 & 0.960945 \\
\hline SO (Q) & $3.1284 \times 10^{6}$ & 1 & $3.1284 \times 10^{6}$ & 0.1380 & 0.712513 \\
\hline $\mathrm{CuSO}_{4}(\mathrm{~L})$ & $1.8663 \times 10^{9}$ & 1 & $1.8663 \times 10^{9}$ & 82.3290 & 0.000000 \\
\hline $\mathrm{CuSO}_{4}(\mathrm{Q})$ & $3.2743 \times 10^{8}$ & 1 & $3.2743 \times 10^{8}$ & 14.4442 & 0.000554 \\
\hline TJM (L) by SO (L) & $1.0752 \times 10^{6}$ & 1 & $1.0752 \times 10^{6}$ & 0.0474 & 0.828857 \\
\hline TJM (L) by $\mathrm{CuSO}_{4}(\mathrm{~L})$ & $2.8895 \times 10^{8}$ & 1 & $2.8895 \times 10^{8}$ & 12.7466 & 0.001060 \\
\hline $\mathrm{SO}(\mathrm{L})$ by $\mathrm{CuSO}_{4}(\mathrm{~L})$ & $1.0385 \times 10^{8}$ & 1 & $1.0385 \times 10^{8}$ & 4.5812 & 0.039371 \\
\hline Error & $7.9341 \times 10^{8}$ & 35 & $2.2668 \times 10^{7}$ & & \\
\hline Total & $1.3759 \times 10^{10}$ & 44 & & & \\
\hline
\end{tabular}
and model

Table 4 ANOVA of DOE performed over the response variable: laccase activity on Day 14

L: linear interaction; Q: quadratic interaction; TJM: tomato juice medium; SO: soybean oil 
Three-dimensional response surface plots of laccase production based on the model were further generated combining two factors and enzyme activity as response variables; the resting factor for each plot remained at medium level. Fig. 3a indicates that increasing tomato juice medium concentration and selecting a lower level of $\mathrm{CuSO}_{4}$ were beneficial. The interaction between both variables was reflected in the shape of the plot. An important interaction between $\mathrm{CuSO}_{4}$ and soybean oil could be observed maintaining tomato juice at medium level (Fig. 3b). There is no significant effect in the different concentrations of soybean oil and only the tomato juice medium is relevant (Fig. 3c).
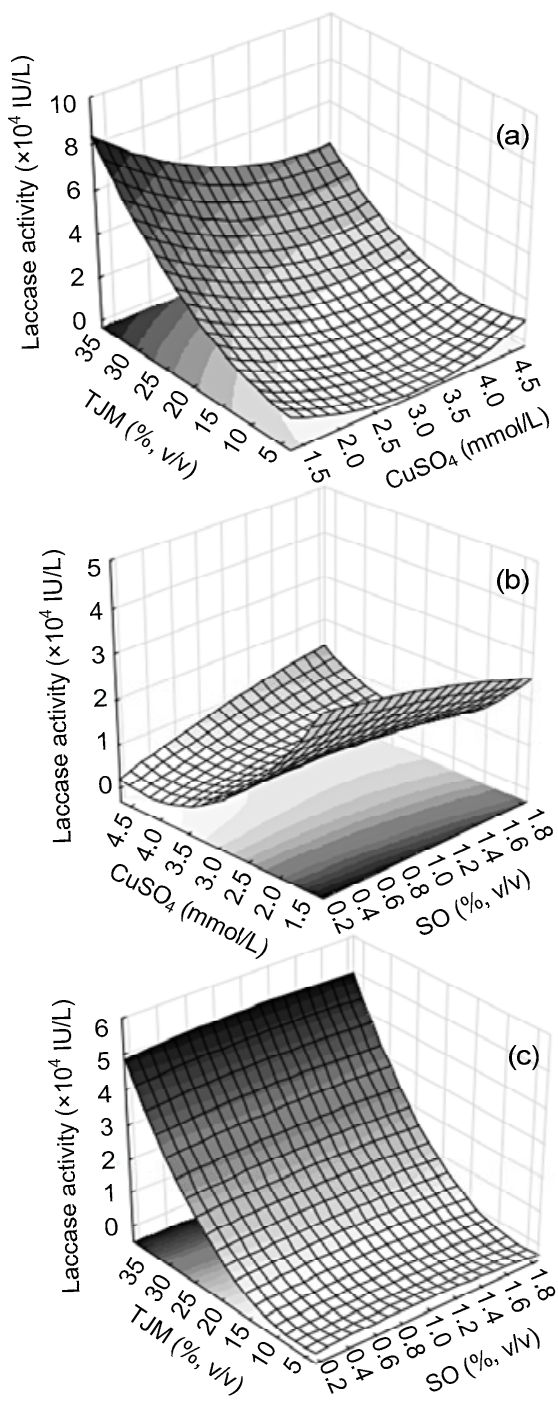

Fig. 3 Response surface models for laccase activity on culture Day 14 under DOE conditions

$X$ and $Y$ axis variables: (a) tomato juice medium (TJM) and $\mathrm{CuSO}_{4}$; (b) soybean oil (SO) and $\mathrm{CuSO}_{4}$; (c) TJM and SO

\subsection{Optimal conditions for upscaling laccase production}

The best result obtained in the DOE analysis was first confirmed at flask level (Fig. 4a). In this set of experiments, the culture in tomato juice medium $36.8 \%(\mathrm{v} / \mathrm{v}), \mathrm{CuSO}_{4} 3 \mathrm{mmol} / \mathrm{L}$, and soybean oil $1 \%(\mathrm{v} / \mathrm{v})$ (A00) showed the highest laccase activity reaching a maximum of $77816 \mathrm{IU} / \mathrm{L}$ on Day 14. The control (tomato juice medium 36.8\%) without any inducer achieved up to $11000 \mathrm{IU} / \mathrm{L}$ on Day 14. It was noticed that $\mathrm{A} 00$ had a $32 \%$ higher activity compared with the mean of the DOE (Fig. 4a). The laccase production was scaled up to a 10-L stirred tank bioreactor applying the A00 conditions (Fig. 4b). The highest measured activity was obtained after $13 \mathrm{~d}$ of growth, when laccase activity reached $143000 \mathrm{IU} / \mathrm{L}$. This activity decreased afterwards, with harvesting on Day 15 and $85700 \mathrm{IU} / \mathrm{L}$. The control flasks presented lower laccase production as expected by the DOE model.

The $\mathrm{pH}$ was monitored throughout the fermentation period. The $\mathrm{pH}$ fluctuated from 3.7 to 6.0. After Day 6, it was increased concomitantly with the laccase activity (Fig. 4b).
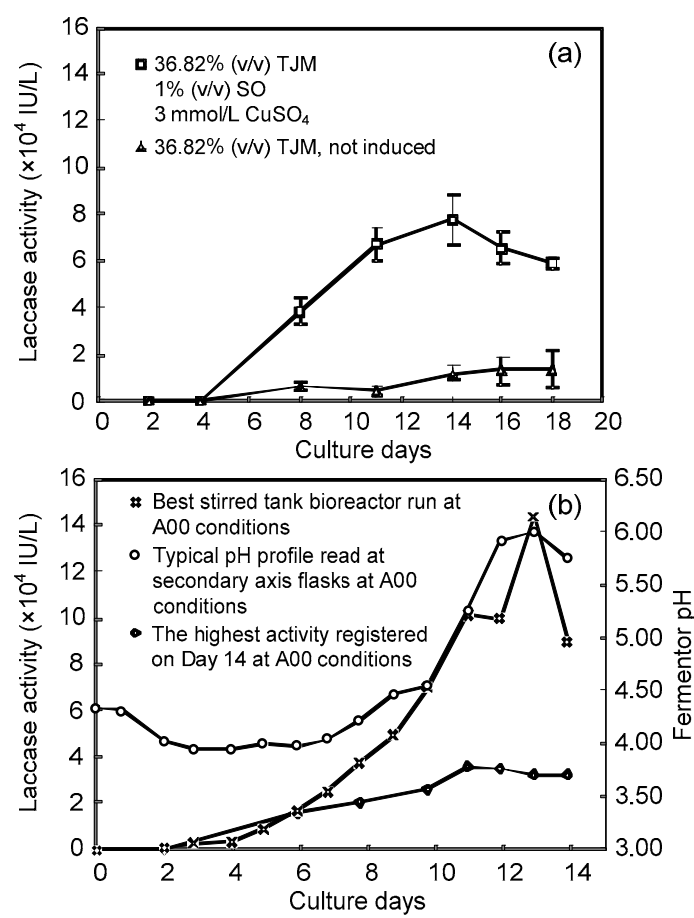

Fig. 4 Confirmation of best treatment conditions for laccase activity

(a) Laccase levels observed from repetition of the best treatment condition of DOE (A00). Data are expressed as mean \pm standard deviation of triplicate experiments. (b) Enzyme activity profile at stirred tank bioreactor level 


\section{Discussion}

Thermostable laccase production from $P$. sanguineus strain CS43 was successfully enhanced and scalable. For the enhancement in this strain, the sequence of separate screening steps for medium and inducers followed by the combination of the best results obtained into a DOE was beneficial as illustrated in Fig. 5. An increment in laccase activity up to 13 times was achieved in comparison with the previous maximum laccase titers at flask level. The cultivation time necessary to reach the highest laccase activities was considerably reduced from 28 to $13 \mathrm{~d}$, with a total productivity increment of 26 times. To the best of our knowledge, the levels of laccase activity achieved by $P$. sanguineus CS43 in stirred tank bioreactor runs $(143000 \mathrm{IU} / \mathrm{L})$ are the highest reported in the literature (Lomascolo et al., 2002; van der Merwe, 2002; Litthauer et al., 2007; Vanhulle et al., 2007a; Dantán-González et al., 2008; Vite-Vallejo et al., 2009; Uzan et al., 2010). Uzan et al. (2010) previously reported high laccase production $(83700 \mathrm{IU} / \mathrm{L})$ in flasks using a Chinese strain of $P$. sanguineus induced by ethanol $(30 \mathrm{~g} / \mathrm{L})$ which is similar to the activity obtained at shaken flask level in the present study. High titers of laccase were also detected (71000 IU/L) using a monokaryotic strain cultivated in a maltose medium with $1 \mathrm{~g} / \mathrm{L}$ of Tween 80 (antifoam and surfactant) and 2,5-xylidine or maize bran rich in ferulic acid as inducers (Lomascolo et al., 2002). In our study, the antifoam 204 mainly used to break the foam in the stirred tank bioreactor runs could have influenced the laccase production in comparison with the flask experiments. Previous studies reported that the addition of Tween 80 to cultures of $P$. sanguineus and $B$. rhodina also induced laccase production (Pointing et al., 2000; Dekker et al., 2007).

The addition of copper has positive effects on the production of laccase in different fungal strains (Baldrian, 2003). It is essential for the synthesis of the active sites of the enzyme (Collins and Dobson, 1997). For $P$. sanguineus $\mathrm{CS} 43$ the best level of $\mathrm{CuSO}_{4}$ was $5 \mathrm{mmol} / \mathrm{L}$ under glucose meat peptone medium conditions. Galhaup and Haltrich (2001) described an optimal induction of laccase for $T$. pubescens at $2 \mathrm{mmol} / \mathrm{L}$ of $\mathrm{CuSO}_{4}$, and comparable results were obtained using $5 \mathrm{mmol} / \mathrm{L}$, although more time was required to reach the maximum activity.

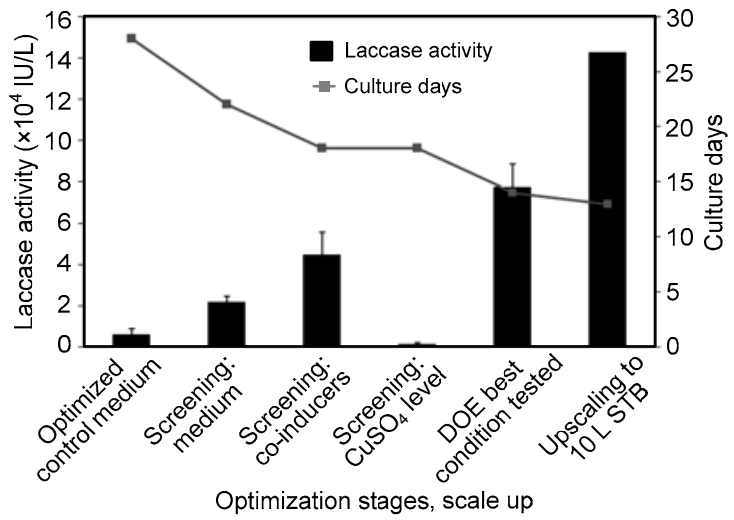

Fig. 5 Optimization advances for laccase production from $P$. sanguineus $\mathrm{CS} 43$

Data are expressed as mean \pm standard deviation of triplicate experiments. DOE: design of experiment; STB: stirred tank bioreactor

In the present study, all tested media in combination with $\mathrm{CuSO}_{4}$ increased laccase activity several folds compared with the induced control medium. Tomato juice had a synergistic positive effect (42fold) on laccase production. The DOE study further demonstrated this important interaction with $\mathrm{CuSO}_{4}$ on enzymatic activity of $P$. sanguineus. Another example of the use of tomato juice and $\mathrm{CuSO}_{4}$ as a good medium for laccase production was reported for the white-rot fungus Cerrena unicolor (Michniewicz et al., 2006). Our model resulting from the CCD indicated that lower levels of $\mathrm{CuSO}_{4}$ in tomato juice medium could provide better results and it needs to be tested in future experiments. Glucose-bactopeptone medium was also identified as a good medium in combination with $\mathrm{CuSO}_{4}$ to induce laccases, achieving about $20000 \mathrm{IU} / \mathrm{L}$ on culture Day 22. Liu et al. (2009) determined from a response surface analysis of the laccase production of $P$. ostreatus that glucose and $\mathrm{Mg}^{2+}$ levels were the most important factors in a similar medium. The use of bran-flake medium achieved up to a 23-fold increase in the activity of CS43 laccases. Dantán-González et al. (2008) tested bran-flake medium for the production of $P$. sanguineus laccases without inducers, and only measured activities of around $6000 \mathrm{IU} / \mathrm{L}$, corresponding to $58 \%$ of that obtained in our study with $\mathrm{CuSO}_{4}(10375 \mathrm{IU} / \mathrm{L})$. Trovaslet et al. (2007) used malt-extract medium (no-inducers) for cultivation of $P$. sanguineus, achieving $850 \mathrm{IU} / \mathrm{L}$ of enzymatic activity after $7-10 \mathrm{~d}$, which was $23 \%$ of the laccase production by the strain CS43 on Day 9 in the presence of $\mathrm{CuSO}_{4}(3574 \mathrm{IU} / \mathrm{L}$; data not shown). 
Most inducers combined with $\mathrm{CuSO}_{4}$ and evaluated in the screening stage enhanced laccase yields. Soybean oil was the best, attaining values of about $45000 \mathrm{IU} / \mathrm{L}$. This vegetable oil was the best inducer by itself in experiments of static cultures of $T$. pubescens on mandarin peelings (Osma et al., 2007). Dekker et al. (2007) also obtained a five-fold increase in the laccase production by $B$. rhodina using soybean oil medium without any other carbon source, so the vegetable oil by itself supported the growth of the fungus. In the present study, in combination with $\mathrm{CuSO}_{4}$, dyes Reactive Blue 19 and Acid Blue 62 were efficient laccase inducers. These dyes have structural similarities to lignin-related laccase substrates (Junghanns et al., 2008). Likewise, the presence of the dyes caused an increase in laccase activity in other Pycnoporus strains (Vanhulle et al., 2007b). Junghanns et al. (2008) obtained positive results in tomato juice medium using Reactive Blue 19 and $\mathrm{CuSO}_{4}$ as inducers over the production of laccases from aquatic ascomycetes. Ferulic acid has been reported as an inducer of laccase activity in Coriolopsis polyzona and other species (Leonowicz et al., 1978; Vanhulle et al., 2007a), but it did not show a significant effect in the case of $P$. sanguineus CS43. Similarly, ferulic acid and gallic acid used as inducers with $\mathrm{CuSO}_{4}$ did not have any relevant impact on laccase production for T. pubescens (Galhaup et al., 2002). In our study, gallic acid did not induce the production of laccase by the native strain.

The model from the CCD indicated that laccase titers could be significantly enhanced by increasing the concentration of the tomato juice in the medium. Junghanns et al. (2008) found a positive correlation between the level of tomato juice and laccase production by aquatic ascomycetes under induced and non-induced conditions. Our findings revealed that laccase activity enhancement also occurred in tomato juice medium without external inducers, as the activity achieved was higher (11000 IU/L) than that produced in the optimized glucose-meat peptone medium and $\mathrm{CuSO}_{4}$. This medium served as a source of carbon and nitrogen for the growth of $P$. sanguineus and also might induce the enzyme production on account of its phenolic compounds as flavonoids and tannic acid (Carbajo et al., 2002; Ullrich et al., 2005).

Soybean oil in addition to $\mathrm{CuSO}_{4}$ improved the laccase activity in the control and tomato juice me- dium cultures. Although their optimal levels were not established in tomato juice medium, their concentration should be reduced as predicted by the model to achieve high laccase levels. This relevant interaction between both components requires an experimental design to examine the synergistic effects and determine better levels.

The $\mathrm{pH}$ was another parameter analyzed during the stirred tank bioreactor runs. After Day 6, the $\mathrm{pH}$ was directly related to laccase production, and it could be used as an indicator of the time to harvest under these operation conditions. Using a $\mathrm{pH}$ sensor and control system, the harvest time could be automated, maximizing laccase productivity. Chu et al. (1992) used variation in $\mathrm{pH}$ for the control process of an alkaline protease production. Interestingly, a similar pattern of color was observed for the fungal cultures during various stirred tank bioreactor runs. At the beginning, the medium was an orange color, mainly due to the tomato juice; this color changed to white-beige on culture Day 5. The culture color was subsequently light brown and continued to darken from Day 7 until the end of the experiment. This probably was associated with the pigments secreted by the fungus, such as melanin. One possible function of laccases is related to the copper-induced formation of melanin (Baldrian, 2003). Dark mycelia were reported when $T$. pubescens was grown in the presence of copper and higher concentration of melanin by increasing this micro-element in the growth medium (Galhaup and Haltrich, 2001).

The data presented here additionally propose that the native strain CS43 of $P$. sanguineus is an ideal candidate for over-production of highly thermostable laccases in an inexpensive medium composed of tomato juice, $\mathrm{CuSO}_{4}$ and soybean oil without the use of hazardous substances such as 2,6-xylidine or other fungal laccase inducers. Results further provide the basis for future development of industrial processes or non-GMO requirements as free or immobilized enzyme. Our research team has already begun the process of separation, purification, and partial sequencing of three laccase isoforms expressed in these culture conditions.

\section{Acknowledgements}

The authors thank the Chair of Environmental Bioprocesses, Tecnológico de Monterrey, Mexico for the technical support given to this work. 


\section{Compliance with ethics guidelines}

Leticia I. RAMÍREZ-CAVAZOS, Charles JUNGHANNS, Rakesh NAIR, Diana L. CÁRDENAS-CHÁVEZ, Carlos HERNÁNDEZ-LUNA, Spiros N. AGATHOS, and Roberto PARRA declare that they have no conflict of interest.

This article does not contain any studies with human or animal subjects performed by any of the authors.

\section{References}

Baldrian, P., 2003. Interactions of heavy metals with white-rot fungi. Enzyme Microb. Technol., 32(1):78-91. [doi:10. 1016/S0141-0229(02)00245-4]

Bertrand, T., Jolivalt, C., Briozzo, P., et al., 2002. Crystal structure of a four-copper laccase complexed with an arylamine: insights into substrate recognition and correlation with kinetics. Biochemistry, 41(23):7325-7333. [doi:10.1021/bi0201318]

Bollag, J.M., Leonowicz, A., 1984. Comparative studies of extracellular fungal laccases. Appl. Environ. Microbiol., 48(4):849-854.

Carbajo, J., Junca, H., Terrón, M., et al., 2002. Tannic acid induces transcription of laccase gene cglccl in the white-rot fungus Coriolopsis gallica. Can. J. Microbiol., 48(12):1041-1047. [doi:10.1139/w02-107]

Chu, I.M., Lee, C., Li, T.S., 1992. Production and degradation of alkaline protease in batch cultures of Bacillus subtilis ATCC 14416. Enzyme Microb. Technol., 14(9):755-761. [doi:10.1016/0141-0229(92)90116-6]

Collins, P.J., Dobson, A.D., 1997. Regulation of laccase gene transcription in Trametes versicolor. Appl. Environ. Microbiol., 63(9):3444-3450.

Dantán-González, E., Vite-Vallejo, O., Martínez-Anaya, C., et al., 2008. Production of two novel laccase isoforms by a thermotolerant strain of Pycnoporus sanguineus isolated from an oil-polluted tropical habitat. Int. Microbiol., 11:163-169. [doi:10.2436/20.1501.01.56]

Dekker, R.F., Barbosa, A.M., Giese, E.C., et al., 2007. Influence of nutrients on enhancing laccase production by Botryosphaeria rhodina MAMB-05. Int. Microbiol., 10(3): 177-185. [doi:10.2436/20.1501.01.25]

Eggert, C., Temp, U., Erikkson, K.E.L., 1996. The ligninolytic system of the white-rot fungus Pycnoporus cinnabarinus: purification and characterization of the laccase. Appl. Environ. Microbiol., 62(4):1151-1158.

Galhaup, C., Haltrich, D., 2001. Enhanced formation of laccase activity by the white rot fungus Trametes pubescens in the presence of copper. Appl. Microbiol. Biotechnol., 56(1-2):225-232. [doi:10.1007/s002530100636]

Galhaup, C., Wagner, H., Hinterstoisser, B., et al., 2002. Increased production of laccase by the wood-degrading basidiomycete Trametes pubescens. Enzyme Microb. Technol., 30(4):529-536. [doi:10.1016/S0141-0229(01) 00522-1]

Gochev, V.K., Krastanov, A.I., 2007. Fungal laccases. Bulg. J. Agric. Sci., 13:75-83.

Hernández-Luna, C., Gutiérrez-Soto, G., Salcedo-Martinez, S.,
2008. Screening for decolorizing basidiomycetes in Mexico. W. J. Microbiol. Biotechnol., 24(4):465-473. [doi:10.1007/s11274-007-9495-3]

Junghanns, C., Parra, R., Keshavarz, T., et al., 2008. Towards higher laccase activities produced by aquatic ascomycetous fungi through combination of elicitors and an alternative substrate. Eng. Life Sci., 8(3):277-285. [doi:10. 1002/elsc.200800042]

Kudanga, T., Nyanhongo, G.S., Guebitz, G.M., et al., 2011. Potential applications of laccase-mediated coupling and grafting reactions: a review. Enzyme Microb. Technol., 48(3):195-208. [doi:10.1016/j.enzmictec.2010.11.007]

Kunamneni, A., Ballesteros, A., Plou, F.J., et al., 2007. Fungal laccase - a versatile enzyme for biotechnological applications. In: Mendez-Vilas, A. (Ed.), Communicating Current Research and Educational Topics and Trends in Applied Microbiology. Formatex-Badajoz, Spain, p.233244.

Lee, I.Y., Jung, K.H., Lee, C.H., et al., 1999. Enhanced production of laccase in Trametes versicolor by the addition of ethanol. Biotechnol. Lett., 21(11):965-968. [doi:10.1023/A:1005646812381]

Leonowicz, A., Trojanowski, J., Orlicz, B., 1978. Induction of laccase in Basidiomycetes: apparent activity of the inducible and constitutive forms of the enzyme with phenolic substrates. Acta Biochim. Pol., 25(4):369-378.

Liers, C., Ullrich, R., Pecyna, M., et al., 2007. Production, purification and partial enzymatic and molecular characterization of a laccase from the wood-rotting ascomycete Xylaria polymorpha. Enzyme Microb. Technol., 41(6-7): 785-793. [doi:10.1016/j.enzmictec.2007.07.002]

Litthauer, D., van Vuuren, M.J., van Tonder, A., et al., 2007. Purification and kinetics of a thermostable laccase from Pycnoporus sanguineus (SCC 108). Enzyme Microb. Technol., 40(4):563-568. [doi:10.1016/j.enzmictec. 2006. 05.011]

Liu, L., Lin, Z., Zheng, T., et al., 2009. Fermentation optimization and characterization of the laccase from Plerotus ostreatus strain 10969. Enzyme Microb. Technol., 44(6-7): 426-433. [doi:10.1016/j.enzmictec.2009.02.008]

Lomascolo, A., Cayol, J.L., Roche, M., et al., 2002. Molecular clustering of Pycnoporus strains from various geographic origins and isolation of monokariotic strains for laccase hyperproduction. Mycol. Res., 106(10):1193-1203. [doi: 10.1017/S0953756202006494]

Michniewicz, A., Ullrich, R., Ledakowicz, S., et al., 2006. The white-rot fungus Cerrena unicolor strain 137 produces two laccase isoforms with different physico-chemical and catalytic properties. Appl. Microbiol. Biotechnol., 69(6): 682-688. [doi:10.1007/s00253-005-0015-9]

Mueangtoom, K., Kittl, R., Mann, O., et al., 2010. Low pH dye decolorization with ascomycete Lamprospora wrightii laccase. Biotechnol. J., 5(8):857-870. [doi:10.1002/biot. 201000120]

Nair, R.R., Demarche, P., Agathos, S.N., 2013. Formulation and characterization of an immobilized laccase biocatalyst and its application to eliminate organic micropollutants 
in wastewater. N. Biotechnol., 30(6):814-823. [doi:10. 1016/j.nbt.2012.12.004]

Osma, J.F., Saravia, V., Toca-Herrera, J., et al., 2007. Mandarin peelings: the best carbon source to produce laccase by static cultures of Trametes pubescens. Chemosphere, 67(8):1677-1680. [doi:10.1016/j.chemosphere.2006.11.051]

Osma, J.F., Toca-Herrera, J.L., Rodríguez-Couto, S., 2011. Cost analysis in laccase production. J. Environ. Manage., 92(11):2907-2912. [doi:10.1016/j.jenvman.2011.06.052]

Palmieri, G., Giardina, P., Bianco, C., et al., 2000. Copper induction of laccase isoenzymes in the ligninolytic fungus Pleurotus ostreatus. Appl. Environ. Microbiol., 66(3): 920-924. [doi:10.1128/AEM.66.3.920-924.2000]

Pointing, S.B., Jones, E., Vrijmoed, L., 2000. Optimization of laccase production by Pycnoporus sanguineus in submerged liquid culture. Mycologia, 92(1):139-144. [doi:10. 2307/3761458]

Rodríguez-Couto, S., Toca-Herrera, J.L., 2007. Laccase production at reactor scale by filamentous fungi. Biotechnol. $A d v .$, 25(6):558-569. [doi:10.1016/j.biotechadv.2007.07. 002]

Rodríguez-Couto, S., Osma, J.F., Toca-Herrera, J.L., 2009. Removal of synthetic dyes by an eco-friendly strategy. Eng. Life Sci., 9(2):116-123. [doi:10.1002/elsc.200800088]

Rogalski, J., Janusz, G., Legiec, D., et al., 2011. Purification of extracellular laccase from Rhizoctonia praticola. J. Fac. Agric., 56(1):1-7.

Trovaslet, M., Estelle, E., Guiavarc'h, Y., et al., 2007. Potential of a Pycnoporus sanguineus laccase in bioremediation of wastewater and kinetic activation in the presence of an anthraquinonic acid dye. Enzyme Microb. Technol., 41(3): 368-376. [doi:10.1016/j.enzmictec.2007.03.007]

Ullrich, R., Huong, L.M., Dung, N.L., et al., 2005. Laccase from the medicinal mushroom Agaricus blazei: production, purification and characterization. Appl. Microbiol. Biotechnol., 67(3):357-363. [doi:10.1007/s00253-0041861-6]

Uzan, E., Nousiainen, P., Balland, V., et al., 2010. High redox potential laccases from the ligninolytic fungi Pycnoporus coccineus and Pycnoporus sanguineus suitable for white biotechnology: from gene cloning to enzyme characterization and applications. J. Appl. Microbiol., 108(6): 2199-2213. [doi:10.1111/j.1365-2672.2009.04623.x]

van der Merwe, J.J., 2002. Production of Laccase by the White-Rot Fungus Pycnoporus sanguineus. MS Thesis, University of the Free State, Bloemfontein, South Africa.

Vanhulle, S., Radman, R., Parra, R., et al., 2007a. Effect of mannan oligosaccharide elicitor and ferulic acid on enhancement of laccases. Enzyme Microb. Technol., 40(7): 1712-1718. [doi:10.1016/j.enzmictec.2006.10.002]

Vanhulle, S., Enaud, E., Trovaslet, M., et al., 2007b. Overlap of laccases/cellobiose dehydrogenase activities during the decolourisation of anthraquinonic dyes with close chemical structures by Pycnoporus strains. Enzyme Microb. Technol., 40(7):1723-1731. [doi:10.1016/j.enzmictec.2006. 10.033]

Vite-Vallejo, O., Palomares, L.A., Dantán-González, E., et al., 2009. The role of $N$-glycosylation on the enzymatic activity of a Pycnoporus sanguineus laccase. Enzyme Microb. Technol., 45(3):233-239. [doi:10.1016/j.enzmictec. 2009.05.007]

\section{中文䈖要:}

本文题目: 中心组合设计方法提高血红密孔菌 (Pycnoporus sanguineus) 耐热漆酶的产量

Enhanced production of thermostable laccases from a native strain of Pycnoporus sanguineus using central composite design

研究目的：优化获得血红密孔菌（P. sanguineus）的最佳培养基组成, 提高耐热漆酶的产量。

创新要点: 获得了目前文献报道的最高水平的漆酶活力。

研究方法: 通过单因素试验研究了不同培养基 (番茄汁、麦麸、麦芽提取物和葡萄糖细菌蛋白胨培养基) 和不同组合诱导剂 (大豆油、阿魏酸、没食子酸、二甲基苯胺、酸性蓝 62 和活性蓝 19 分别 与硫酸铜组合诱导剂) 对 P. sanguineus 产耐热漆酶的影响。在此基础上采用中心组合试验设 计, 进一步研究了番茄汁培养基结合硫酸铜和大豆油组合诱导剂对 P. sanguineus 产耐热漆酶 的影响。利用 SAS10.0 和响应面分析方法对试验结果进行了统计分析和建立回归模型。

重要结论: 通过中心组合设计优化得出 P. sanguineus 产耐热漆酶的最优培养基条件: 以 $36.8 \%$ 番茄汁为 培养基, 以 $3 \mathrm{mmol} / \mathrm{L}$ 硫酸铜和 $1 \%$ 大豆油作为组合诱导剂。该条件下在 $10 \mathrm{~L}$ 搅拌槽生物反 应器中漆酶活力达到了 $143000 \mathrm{IU} / \mathrm{L}$ (2,2'-联氮双(3-乙基苯并噻唑啉-6-磺酸)为底物, $\mathrm{pH}$ 值 为 3.0 )。

关键词组: 漆酶产量; 中心组合设计; 培养基篮选; 诱导剂; 番茄汁; 大豆油; 硫酸铜 